\title{
Clinical importance of circulating immune complexes in human acute lymphoblastic leukemia
}

\author{
Maria V. Croce ${ }^{1}$, Marcela Fejes ${ }^{2}$, Norma Riera ${ }^{2}$, D. A. Minoldo ${ }^{2}$, and Amada Segal-Eiras ${ }^{1}$ \\ ' Department of Pathology, School of Medicine, National University of La Plata, 1900-La Plata, Argentina \\ ${ }^{2}$ Institute of Hematological Research, National Academy of Medicine, Buenos Aires, Argentina
}

Summary. A total of 122 sera from acute lymphoblastic leukemia (ALL) patients were analyzed for circulating immune complexes (CIC) by two methods: the ${ }^{125} \mathrm{I}-\mathrm{C}_{1} \mathrm{q}$ binding assay and the polyethylene glycol precipitation test (PEG). The results were correlated with induction, remission and relapse stages of the disease. Using the first method the levels of CIC in induction were $15.18 \pm 9.15$, with $19 / 29$ positive cases $(65.50 \%), \mathrm{P}<0.001$ compared with controls. In the remission phase the levels were $9.02 \pm 5.62$, $11 / 45(24.49 \%)$ nonsignificant $P$ value, and in relapse they were $16.14 \pm 11.1728 / 48 \quad(58.33 \%) \quad \mathrm{P}<0.001$. The PEG precipitation test results were: $0.33 \pm 0.10,8 / 22(36.36 \%)$; $0.24 \pm 0.11,10 / 48(20.83 \%)$ and $0.28 \pm 0.10,6 / 28(21.42 \%)$, respectively. Thus the values of CIC as measured by PEG in the three clinical of phases ALL did not differ significantly from controls. This contrasts with results obtained by the radioiodinated $\mathrm{C}_{1} q$ binding assay, where the incidence of positive values was significantly higher in induction and in relapse and lower in the remission phase. These observations were extended in sequential vertical studies performed in a group of patients. These results suggest that raised CIC detected by the ${ }^{125} \mathrm{I}-\mathrm{C}_{1} \mathrm{q}$ method may reflect a progressive state in ALL and that quantitation of these immune complexes may provide an adequate biochemical marker for prognosis.

\section{Introduction}

During the last 10 years increasing interest has developed in research studies concerning the possible association of immune complexes with malignant diseases. It has been observed that the inhibition of cell-mediated immune reactions seems to be related to several malignant tumors. There is evidence showing that some soluble factors are inducers of this cellular immune inhibition [18]. These immune complexes may be formed by tumor-associated antigens and specific antitumor antibodies [13]. Their suppressive action on cell-mediated immunity has not been elucidated, although they do appear to block effector $\mathrm{T}$ cell functions [20].

There are several reports concerning the correlation of circulating immune complex (CIC) levels and the clinical status of malignant disease, including leukemia $[1,5,8,15$, $17]$. It has been suggested that immune complexes may in-

Offprint requests to: A. Segal-Eiras duce tumor progression changing the immune response of the host against malignant cells [2]. The present investigation was undertaken to determine more clearly the clinical significance of CIC in acute lymphoblastic leukemia (ALL). The patients were studied over a 3-year period to try to discover a correlation between CIC levels and the clinical stage of the disease.

\section{Materials and methods}

Patients. A total of 122 serum samples from 55 children with ALL were studied for the presence of immune complexes using two methods: the ${ }^{125} \mathrm{I}_{-} \mathrm{C}_{1} \mathrm{q}$ binding assay [29] and the polyethylene glycol precipitation test (PEG) [10]. Sera from 29 patients were analyzed at the time of diagnosis, 45 during remission and 48 at relapse. Also a sequential study of CIC was performed in a group of patients over a period of several months.

Patients were treated according to uniform therapeutic regimens (GATLA: Grupo Argentino para el Tratamiento de la Leucemia Aguda). Patients were classified as being in induction phase, complete remission or relapse. At the time when blood samples were taken, most of the patients were being treated as follows. Briefly, treatment for induction of remission consisted of daily courses with prednisone, L-aspariginase over 4 weeks; vincristine and daunorubicin once per week with a total of four doses followed by cyclophosphamide plus 4 weeks receiving cytarabine and 6-mercaptopurine. Central nervous system involvement was prevented by intrathecal injection of methotrexate and dexamethasone. This therapeutic protocol also included a re-induction of remission treatment. It consisted of continuous administration of dexamethasone plus vincristine and adriamicin weekly and L-aspariginase on each of 4 days over 4 weeks; it was followed by a continuous 2-week treatment with cyclophosphamide and daunorubicin; it was completed with intrathecal methotrexate and dexamethasone.

Serum samples. Blood was taken aseptically from patients and allowed to clot at room temperature for at least $60 \mathrm{~min}$. It was centrifuged at $1,500 \mathrm{~g}$ for $15 \mathrm{~min}$, and sera were then aliquoted into Durham tubes and stored at $-70^{\circ} \mathrm{C}$ until used. Although it has been shown that freezing and thawing do not alter CIC levels [25] each serum sample was thawed out only on the day of the test. As controls, serum samples were collected from 46 normal si- 


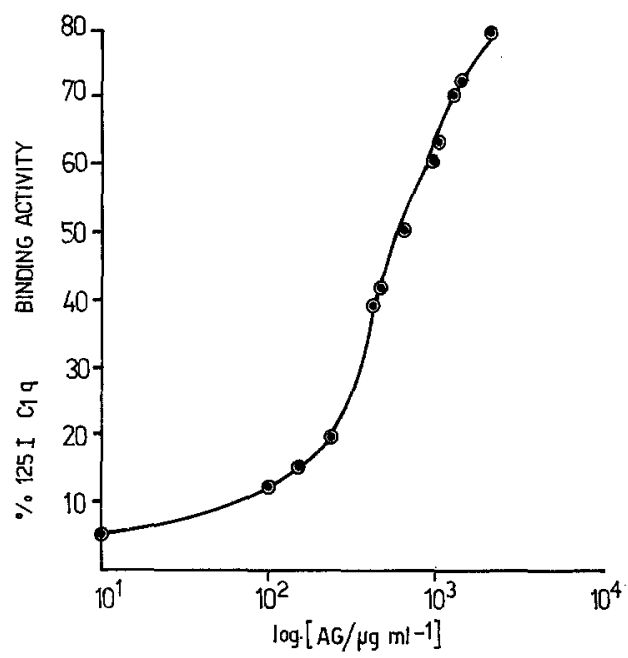

Fig. 1. $\mathrm{C}_{1} q$ binding activity by human gamma globulin aggregates suspended in normal human serum. CIC normal value of $9.00 \%$ corresponded to $55 \mu \mathrm{g} / \mathrm{ml}$ of aggregates

blings of leukemic patients or nonmalignant patients of either sex admitted to The Children's Hospital for hernia, phimosis, ectopic testes and idiopathic scoliosis corrective surgery. These controls had no history of infection for a 2week period prior to blood sampling. All control samples were collected in the same way as in the experimental group.

Detection of circulating immune complexes ${ }^{125} I-C_{1} q$ binding assay. This assay for CIC detection is related to the property of immune complexes to react with one of their receptors, the first complement component. This method measures the quantity of radioiodinated $\mathrm{C}_{1} \mathrm{q}$ combined to immune complexes in the test serum. The $C_{1} q$ was isolated from a pool of fresh human serum as previously described [28] and radiolabeled with ${ }^{125} \mathrm{I}-\mathrm{C}_{1} \mathrm{q}$ by means of the lactoperoxidase method [14].

The ${ }^{125} \mathrm{I}-\mathrm{C}_{1} \mathrm{q}$; binding assay was performed as previously described [29], together with the slight modification by a short incubation of the serum samples with heparin before the first step. This modification suggested by Baldwin et al. [3] improves the discrimination between patients and control studies. In each test between five and seven normal serum samples were tested to determine the normal range, all sera were tested in duplicate and in three different assays. Also, in each assay as a positive control, heat aggregated human immunoglobulin $\left(63^{\circ} \mathrm{C}\right.$ for $\left.20 \mathrm{~min}\right)$ obtained from Cohn fraction II (Sigma, Chemical Company, St. Louis,
MO. 63178, USA) was used diluted in normal human serum. Results were expressed as the percentage of ${ }^{125} \mathrm{I}-\mathrm{C}_{1} \mathrm{q}$ in experimental precipitates compared to ${ }^{125} \mathrm{I}-\mathrm{C}_{1} \mathrm{q}$ in precipitates of tubes containing $50 \mu \mathrm{l}$ normal human serum and $50 \mu 1{ }^{125} \mathrm{I}-\mathrm{C}_{1} \mathrm{q}$ precipitated with $20 \%$ trichloroacetic acid. The normal value of CIC by this assay was $9.00 \pm 2.00 \quad(x \pm 2 S D)$. This value was equivalent to $55 \mu \mathrm{g} / \mathrm{ml}$ heat aggregated human immunoglobulin (Fig. 1). The ${ }^{125} \mathrm{I}-\mathrm{C}_{1} \mathrm{q}$ binding activity was considered elevated if the results were $2 \mathrm{SD}$ above the normal range.

The polyethylene glycol precipitation test (PEG). This was a modification of the technique previously described $[10,11$, 24]. Briefly, $0.1 \mathrm{ml}$ test sera was diluted to $0.9 \mathrm{ml}$ in borate buffer $0.1 \mathrm{M}, \mathrm{pH} 8.4$ and $1.0 \mathrm{ml}$ of $8 \%$ PEG in borate buffer was added. The mixture was incubated at $4{ }^{\circ} \mathrm{C}$ for $18 \mathrm{~h}$ and then centrifuged at $2,000 \mathrm{~g}$ at $4{ }^{\circ} \mathrm{C}$ for $30 \mathrm{~min}$. The precipitate was suspended and vortexed in $2 \mathrm{ml}$ PEG. Samples were centrifuged at $2,000 \mathrm{~g}$ for $30 \mathrm{~min}$. The supernatant was discarded and the precipitate dissolved in $0.1 \mathrm{ml} \mathrm{NaOH}$ by agitation; the optical density was determined at $280 \mathrm{~nm}$. The normal value was $0.22 \pm 0.05$ $(x \pm 2 S D)$, and therefore values over 0.27 were considered as positive.

Statistical analysis was carried out using the Student's $t$-test.

\section{Results}

\section{CIC levels using the radioiodinated $C_{1} q$ binding test}

In order to determine the extent to which CIC levels could be used to assess prognosis, a sequential study was performed in a group of ALL patients, 29 in induction, 48 in relapse and 45 in remission. The CIC were determined in a total of 122 sera from $55 \mathrm{ALL}$ patients, and the results are shown in Table 1. Under the induction of remission treatment (blastic stage) CIC values were $15.78 \pm 9.15$ with $19 / 29$ positives $(65.50 \%)(P<0.001$ compared with normals). In remission the mean value was $9.02 \pm 5,62,11 / 45$ positives $(24.49 \%)$, and in relapse phase the mean value was $16.59 \pm 11.17,28 / 48(58.33 \%)$ positives $(\mathrm{P} \pm 0.001$ in relation to normals). Compared with the sera from 46 controls the mean value of $\mathrm{C}_{1} \mathrm{q}$ binding activity was significantly increased in patients in induction and in relapse stages. Conversely, CIC levels were no longer detectable in sera from the remission phase group and similar to controls $(\mathrm{P}>0.5)$.

Figure 2 shows the CIC results obtained in patients in relapse followed by a remission phase. In most of them the raised CIC levels were prevalently associated with the acute phase of leukemia with normal values in remission. In Fig. 3 the CIC values obtained in sera from patients in

Table 1. Incidence of circulating immune complexes in patients with ALL according to the stage of disease using the ${ }^{125} \mathrm{I}-\mathrm{C}_{1} \mathrm{q}$ bindig assay

\begin{tabular}{|c|c|c|c|c|c|c|c|}
\hline Stage & & $n$ & $\bar{x}$ & ${ }^{\delta} n-1$ & $P^{*}$ & $+/$ totals & $\%$ \\
\hline Induction & & 29 & 15.18 & 9.15 & $<0.001$ & $19 / 29$ & 65.50 \\
\hline Remission & $\mathrm{fr}_{1}$ & 45 & 9.02 & 5.62 & N.S. & $11 / 45$ & 24.49 \\
\hline Relapse & & 48 & 16.14 & 11.17 & $<0.001$ & $28 / 48$ & 58.33 \\
\hline
\end{tabular}

" $\mathrm{p}$ value comparing with controls

Normal value: $9.00 \pm 2.00$, ie., $\bar{x}+2 \mathrm{SD} ; 11 \%$ is the upper limit of normal values

N.S.: not significant $(P>0.5)$ 


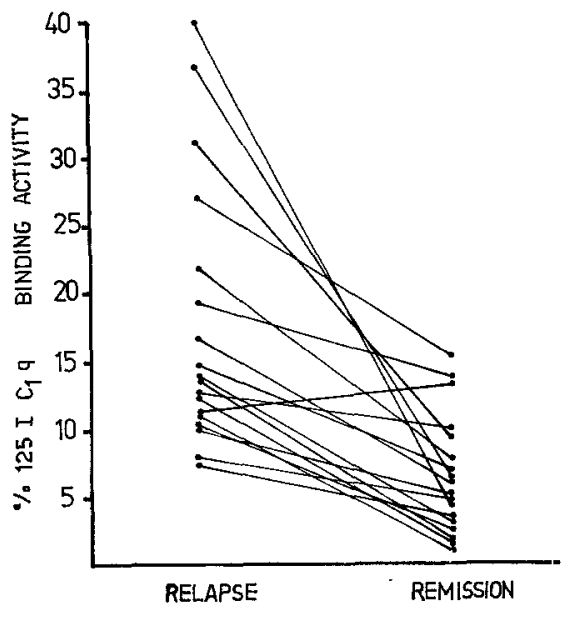

Fig. 2. Evolution of serum $C_{1} q$ binding activity in 18 patients with ALL according to two stages of disease: relapse and remission. Normal value was $9.00 \pm 2.00$

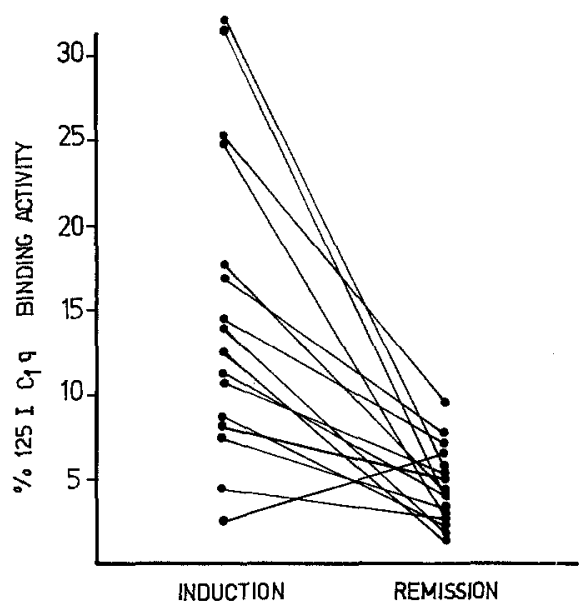

Fig. 3. Evolution of serum $C_{1} q$ binding activity in 16 patients with ALL according to two stages of disease: induction and remission. Normal value was up to $9.00 \pm 2.00$

induction followed by remission are shown. Results were significantly lower when patients went into remission.

In a small group of ALL patients a sequential study of CIC was done in the three phases of disease: induction, remission and relapse, and the results are shown in Fig. 4. Most of the patients showed high levels in induction phase. Only 1 presented a low value. In the 6 patients CIC levels were normal in remission while in relapse 4 yielded high values and 2 border line percentages.

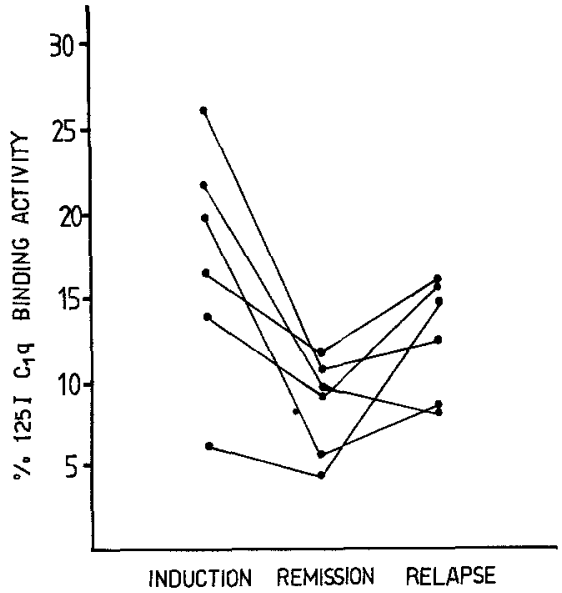

Fig. 4. Evolution of serum ${ }^{125} \mathrm{I}-\mathrm{C}_{1} \mathrm{q}$ binding activity in six patients with ALL according to three phases of the disease: induction, remission and relapse

\section{CIC levels using the PEG precipitation test}

Most of the sera studied using the radioiodinated $C_{1} q$ binding test were tested for CIC by the PEG precipitation method. A sequential study was performed in the three phases of disease. Patients in induction showed an optical density of $0.33 \pm 0.10 \quad(36 \%$ positives), in remission $0.24 \pm 0.11,10 / 24(20 \%)$ and in relapse $0.28 \pm 0.10,3 / 14$ $(21.42 \%)$ (Table 2).

\section{Discussion}

This study performed using the ${ }^{125} \mathrm{I}-\mathrm{C}_{1} \mathrm{q}$ binding assay and the PEG precipitation test confirms previous reports on the presence of CIC in sera from patients with ALL. These complexes were found to be reactive with $\mathrm{C}_{1} q$ and precipitable by PEG. Results obtained by both methods indicate that patients with ALL have high levels of antigen-antibody complexes. The amount detected is related to the status of disease; in particular a high percentage of immune complexes were found in the sera of ALL patients with a high number of blasts (acute phase of disease). It has been demonstrated that leukemic blasts display large amounts of strong immunogenic leukemia-associated antigens [9]. In ALL there is a proliferation of nondifferentiated lymphocytes and the presence of immune complexes in the plasma of these patients suggests that there are enough lymphocytes which remain capable of inducing antibody response. Therefore, immunogens derived from leukemic cells may form immune complexes when they combine with their corresponding antibody. These immune com-

Table 2. Incidence of circulating immune complexes in patients with ALL according to the stage of disease using the PEG precipitation assay

\begin{tabular}{lllllrl}
\hline Stage & $n$ & $\bar{x}$ & $\delta_{\mathrm{n}-1}$ & $\mathrm{P}^{*}$ & $+/$ totals & $\%$ \\
\hline Induction & 22 & 0.33 & 0.10 & $<0.001$ & $8 / 22$ & 36.36 \\
Remission & 48 & 0.24 & 0.11 & $<0.005$ & $10 / 48$ & 20.83 \\
Relapse & 28 & 0.28 & 0.10 & $<0.001$ & $6 / 28$ & 21.42 \\
\hline
\end{tabular}

" $\mathrm{p}$ value comparing with controls

Normal value: $0.22 \pm 0.05$, i.e., 0.27 was considered the upper limit of normal values 
plexes do not induce vasculitis or serum sickness although they may produce immune complex diseases because of their size. Nevertheless, none of these leukemic patients showed clinical or laboratory data suggesting a membranous glomerulonephritis. Possibly, immune complexes in ALL patients may be considered as terminal stage immune complexes [27] which are unable to fix onto cell membrane receptors or to activate complement components. Therefore, they have lost their injuring capacity. Another fact which is difficult to assess is why the destruction of many malignant cells by chemotherapy does not increase CIC levels.

In the whole group of patients there was a striking difference in CIC levels between induction and remission phases and between relapse and remission with $\mathrm{P}<0.001$ for both groups. No differences of CIC levels were observed between patients in induction and in relapse phases. In remission CIC values were decreased, yielding normal levels $(9.02 \pm 5.62)$. The present findings correlate with those reported by Hubbard et al. [16] who obtained a clear relationship between CIC positive levels and the progressive state of leukemia using the Raji cell immunoassay. Similar results were found by Carpentier et al. [7] in acute myeloid leukemia using the ${ }^{125} \mathrm{I}-\mathrm{C}_{1} q$ binding assay. Also, Euler et al. [12] using the 3\% PEG precipitation test found that the quantification of precipitable immune complexes and their components may be valuable as adjuncts in determining disease activity in Hodgkin's disease. Segal-Eiras et al. [25] found high levels of CIC in osteosarcoma patients, a possible correlation with recurrence/metastasis and the IgG nature of the antibody involved. On the contrary, Minden et al. [19] did not find a relationship between the incidence of relapse and the presence or absence of immune complexes. They also demonstrated the absence of association between antibody response to BCG and a favorable clinical response.

In the present study no correlation was observed between CIC levels and the cellular type of leukemia: T-cell, B-cell or null-cell leukemia. No relationship was found between clinical hemorrhage and thrombocytopenia as other authors have reported [4]. Results correlated strongly with the clinical progression of the disease and development of high numbers of blasts.

In comparison the ${ }^{125} \mathrm{I}-\mathrm{C}_{1} \mathrm{q}$ binding assay is more discriminative than the PEG precipitation assay. Detection of CIC by the first method showed high values in induction and in relapse, and decreased levels in remission. Similar results were obtained by Carpentier et al. [6] applying the same method and also the Raji cell radioassay. Nevertheless, other authors [23] did not find a correlation between CIC levels obtained by the solid-phase bovine conglutinin test and clinical status in nonlymphatic leukemia. Clague et al. [8], using the $C_{1} q$ radioiodinated assay did not observe any correlation between the presence of CIC and the prognosis in ALL, although they observed a strong correlation with a history of recent infection.

The PEG precipitation assay showed high CIC levels in induction only in $36 \%$ of the patients and about $20 \%$ in remission and in relapse phases. A possible explanation may be that different CIC detection methods may measure immune complexes of different nature, structure, and stability. The PEG precipiation assay may detect immune complexes of relative instability in comparison with those detected by the ${ }^{125} \mathrm{I}-\mathrm{C}_{1} \mathrm{q}$ binding assay. For instance, $\mathrm{PEG}$ immune complex values fall rapidly following repeated freezing and thawing [21] in gynecological malignancies. Another possibility, based on the report of Soltis and Hasz [26], is to use a final concentration of $2 \%$ PEG to obtain more discriminative results. They achieved a high degree of sensitivity between aggregated immunoglobulin and monomeric IgG.

The demonstration of complexed material with characteristics of precipitable immune complexes in ALL patients in the active stage, i.e., in induction and in relapse, should suggest the basis for studies on the prognostic usefulness of CIC.

Further investigations may facilitate the deciphering of the nature of the antigenic fraction and the antibodies involved in patients with ALL. Finally, studies related to the effect of CIC on interleukin production by mononuclear cells during progressive malignancies, as some authors have demonstrated in experimental animals [22], may allow a better understanding of other CIC effects.

Acknowledgements. These studies were supported by the Consejo Nacional de Investigaciones Científicas y Técnicas (CONICET), Buenos Aires, Argentina. We gratefully thank Dr. Santiago Pavlovsky, Instituto de Investigaciones Hematológicas, Academia Nacional de Medicina, Buenos Aires, Argentina for provision of serum samples and clinical data of patients in his care and Miss Silvia Moya for editorial assistance.

\section{References}

1. Amlot PL, Slaney JM, Williams BD (1976) Circulating immune complexes and symptoms in Hodgkin's disease. Lancet $1: 449$

2. Baldwin RW, Robins RA (1976) Factors interfering with immunological rejection of tumors. Brit Med Bull 32: 118

3. Baldwin RW, Byers VS, Robins RA (1979) Circulating immune complexes in cancer: characterization and potential as tumor markers. Behring Inst Mitt 64:63

4. Balestrieri G, Tincani A, Cattaneo R, Rossi G, Verzura $P$, Marini G, Calculli G, Ferremi P, Marinone G (1981) Circulating immune complexes in human acute leukemia. $\mathrm{Br} \mathrm{J}$ Haematol 49:269

5. Carpentier NA, Lange GT, Fiere DM, Fournie GL, Lambert PH, Miescher PA (1977) The clinical relevance of circulating immune complexes in human leukemia. Association in acute leukemia of the presence of immune complexes with unfavourable prognosis. J Clin Invest 60:874

6. Carpentier NA, Louis JA, Lambert PH, Cerottini JC (1981) Immune complexes in leukemia and adult malignancies. In Serrou B, Rosenfeld C (eds) Human cancer immunology, volume $\mathrm{I}$, immune complexes and plasma exchanges in cancer patients. Elsevier North Holland Biochemical Press, Amsterdam, New York, Oxford pp 111

7. Carpentier NA, Fiere DM, Schuh D, Lange GT, Lambert PH (1982) Circulating immune complexes and the prognosis of acute myeloid leukemia. N Engl J Med 4: 1175

8. Clague RB, Kumar S, Hann IM, Morris Jones PH, Lennox Holt PJ (1978) Relevance of cirulating immune complexes in childhood acute lymphoblastic leukemia. Int J Cancer 22: 227

9. Cotropia JP, Gutterman JU, Hersh FM, Granatek CH, Mavligit GM (1976) Antigen expression and cell surface properties of human leukemia blasts. Ann NY Acad Sci 276: 146

10. Creighton WD, Lambert PH, Miescher PA (1973) Detection of antibodies and soluble antigen-antibody complexes by precipitation with polyethylene glycol. J Immunol 11: 4, 1219

11. Digeon M, Laver M, Riza J, Bach JF (1977) Detection of circulating immune complexes in human sera by simplified assays with polyethylene glycol. J Immunol Meth 16: 165 
12. Euler HH, Béress R, Modenhauer I, Löffler H (1983) Precipitable immune complexes in Hodgkin's disease. Int J Cancer 32: 437

13. Hellström KE, Hellström I (1977) Immunologic enhancement of tumor growth. In: Green I, Cohen S, McCluskey RT (eds) Mechanisms of tumor immunology. J Wiley, New York, pp 147

14. Heusser C, Boesman M, Nordin JH, Isliker H (1973) Effect of chemical and enzymatic radioiodination on in vitro human $\mathrm{C}_{1} \mathrm{q}$ activity. J Immunol 110:820

15. Höffken K, Meredith ID, Robins RA, Baldwin RW, Davies CJ, Blamey RW (1977) Circulating immune complexes in patients with breast cancer. Brit Med J 2:218

16. Hubbard RA, Aggio MC, Lozzio BB, Wust CJ (1981) Correlation of circulating immune complexes and disease status in patients with leukemia. Clin Exp Immunol 43: 46

17. Jose DG, Ekert H, Colebatch J, Waters K, Wilson F, O'Keefe $D$ (1976) Immune function at diagnosis in relation to responses to therapy in acute lymphocytic leukemia of childhood. Blood 47: 1011

18. Kamo I, Friedman $H$ (1977) Immunosuppressive factors in cancer. Adv Cancer Res 25: 271

19. Minden P, Furman Odom L, Tubergen DG, Andrist Hardtke M, Sharpton TR, Rose B, Zlotnick A, Carr RI (1980) Immune complexes in children with leukemia. Cancer 45:460

20. Moretta T, Mingari MC, Romanzi CA (1978) Loss of receptors for IgG from human $\mathrm{T}$ lymphocytes exposed to IgG immune complexes. Nature 272:618

21. Poulton TA, Mooney NA, Nineham LJ, Hay FC (1983) Characteristics of immune complexes detectable by two independent assays in gynaecological malignancies. Clin Exp Immunol 53: 573
22. Ravikumar $T$, Steele $G$, Rodrick $M$, Roos D, Wilson $R$, Lahey S, Wright D, Munroe A, King V (1984) Effect of tumor growth on interleukins and circulating immune unresponsiveness. Cancer 53: 1373

23. Rossi G, Balestrieri G, Tincani A, Ferremi P, Marinone G (1983) Detection of circulating immune complexes in acute nonlymphatic leukemia: is it reliable? Acta Haemat 69: 404

24. Santoro F, Wattre P, Dessaint JP, Capron A (1977) Hepatitis $B$ circulating immune complexes. Characterization by radioimmunoprecipitation-PEG assay (RIPEGA) J Immunol Methods 15:201

25. Segal-Eiras A, Robins RA, Baldwin RW, Byers VS (1980) Circulating immune complexes in patients with bone tumors. Int J Cancer 25: 735

26. Soltis RD, Hasz DE (1983) The effect of serum $I_{g}$ concentration on immune complexes detection by polyethylene glycol. J Immunol Methods 57: 275

27. Takahashi M, Takahashi S, Hirose S (1980) Solubilization of antigen-antibody complexes: a new function of complement as a regulator of immune reactions. Prog Allergy 27:134

28. Yonemasu K, Stroud RM (1971) C q rapid purification method for preparation of monospecific antisera and for biochemical studies. J Immunol 106: 304

29. Zubler R, Lange G, Lambert PH, Miescher PA (1976) Detection of immune complexes in unheated sera by a modified ${ }^{125} \mathrm{I}_{-} \mathrm{C}_{1} \mathrm{q}$ binding test. J Immunol 116:232

Received January 14, 1985/Accepted March 12, 1985 